\title{
El arte como manipulación en Aby Warburg ${ }^{1}$
}

\author{
Arte como manipulação em Aby Warburg
}

\section{Ignacio Uribe Martínez}

Doutor em Estudos da Antiguidade, Medievo e Renascimento pela Universidade de Florença, Itália, profesor associado do Instituto de Filosofia, Pontifícia Universidade Católica de Valparaíso Chile, e-mail: ignacio.uribe@ucv.cl

\section{Resumen}

Al definir al hombre, Aby Warburg pone al centro de su consideración el concepto de manipulación. La existencia humana estaría caracterizada por el contacto con objetos externos, lo cual se aprecia tanto en el uso de utensilios como en la creación artística. Mientras para el primer caso Warburg habla de un sentimiento trágico producto de la extensión de lo orgánico a lo inorgánico del objeto, en el caso del arte la noción de tragedia es omitida. Este artículo propone una interpretación de esta diferencia sostenida en el análisis comparativo de textos de Warburg y de algunos autores que lo influenciaron.

Palabras clave: Warburg. Tragedia. Manipulación. Creación artística. Símbolo.

1 Una versión preliminar de este trabajo fue presentada en el Congreso Nacional de Filosofía desarrollado en la Biblioteca de Santiago de Chile entre el 6 y 9 de Octubre de 2009. 


\section{Resumo}

Ao definir o homem, Aby Warburg põe no centro de sua consideração o conceito de manipulação. A existência humana estaria caracterizada pelo contato com objetos externos, que pode ser vista no uso de utensílios como a criação artística. Enquanto para o primeiro caso Warburg fala de um sentimento trágico, produto da extensão do orgânico ao inorgânico do objeto, no caso da arte a noção de tragédia é omitida. Este artigo propõe uma interpretação desta diferença sustentada na análise comparativa de textos de Warburg e de alguns autores que o influenciaram.

Palavras-chave: Warburg. Tragédia. Manipulação. Criação artística. Símbolo.

\section{Introducción}

Los estudios sobre El ritual de la serpiente, de Aby Warburg (STEINBERG, 1995; SETTIS, 2006), han mostrado la importancia capital que esta obra tiene en el andamiaje teórico del alemán. Sin embargo, ninguna de ellas se ha detenido en las implicancias que el concepto de manipulación tiene para comprender la definición de creación artística de este pensador.

En sus anotaciones para la conferencia del 21 de abril de 1923, Aby Warburg definió al hombre como un animal manipulador:

El punto de partida es mi consideración del hombre como un animal manipulador, cuya actividad consiste en establecer conexiones y separaciones. En el curso de esta actividad el hombre pierde el sentimiento orgánico del yo, ya que la mano le permite tomar cosas reales que, en cuanto objetos inorgánicos, carecen de un sistema nervioso pero que permiten al yo una extensión inorgánica. Ésta es la tragedia del hombre: la manipulación que trasciende su específica extensión orgánica (WARBURG, 2006a, p. 46).

La extensión del yo, la proyección del sujeto sobre el objeto, implica una pérdida de la pureza del primero. El acto de manipular, en sí mismo, es siempre un acto trágico para Warburg. Cada vez que el sujeto anula la distancia con el objeto, entra ineludiblemente en el escenario de la tragedia. Ambos pueden permanecer como entidades relacionadas a condición que el primero 
mantenga intacta su capacidad para volver a lo puramente orgánico. El hombre ha de saber que la herramienta material no puede ni debe definirlo.

Este aspecto de la filosofía warburgiana toma un nuevo giro cuando se trata de la creación artística. Como veremos, al definirla en la Introducción del Atlas de las imágenes - Mnemosyne - pone nuevamente al centro el concepto de manipulación (WARBURG, 2002). Por ser una creación del hombre esta coordenada no debe llamarnos la atención. Sí, en cambio, la omisión de cualquier consideración trágica no obstante los presupuestos parezcan ser los mismos. Si la manipulación del objeto determina la tragedia del hombre, es preciso preguntarse el porqué de su desaparición en la esfera del arte, donde tal condición inicial permite la conformación de la imagen.

A partir del concepto de manipulación, nos proponemos establecer los límites de esta aparente paradoja intentando vislumbrar la presencia y el alcance que Warburg le dio a la idea de tragedia en el arte.

\section{El origen del texto}

En Septiembre de 1895 el historiador de la cultura alemán Aby Warburg, viajó a Estados Unidos con ocasión del matrimonio de su hermano Paul. Una corta permanencia en la ciudad de Nueva York estuvo determinada por el desagrado que le provocó, según sus palabras, "el vacío de la civilización de la América del Este” (WARBURG, 2006a, p. 16).

En este contexto, el interés que había suscitado en Warburg la llamada "biología de las imágenes" y la lectura del etnólogo alemán, Adolf Bastian, ${ }^{2}$ favorecerían su traslado al suroeste del país. Bastian postulaba la necesidad de recolectar datos de las culturas originarias a partir de los cuales podía emerger una nueva ciencia de la psicología humana que permitiese una "estilística de las ideas", un tema que interesaba profundamente a Warburg (GOMBRICH, 2003 , p. 85). De esta manera el historiador inició un viaje a Nuevo México, ${ }^{3}$ hacia lo que entendía como un "objeto real" de investigación basado en la observación. Aquél le proporcionaría los elementos necesarios para comprender

2 Sobre la noción de "biología de las imágenes" - término con el que se conoció una de las corrientes antropológicas del siglo XIX interesada en la construcción de secuencias iconográficas de raíces biológicas - ver: SEVERI, 2004.

3 Una completa reconstrucción del itinerario de Warburg en América se encuentra en NABER, 1988. 
desde una fuente directa los presupuestos que explicasen el vínculo natural o "relación orgánica" - entre el arte y la religión (WARBURG, 2006a, p. 18).

Los recuerdos y fotografías recopilados durante dicha estadía constituyeron la materia de tres conferencias que dictó a comienzos de 1897, el año siguiente de su retorno a Alemania (STEINBERG, 1995, p. 94-95). No obstante estas charlas, la información recolectada debía permanecer sólo como una herramienta metodológica útil en el desarrollo de investigaciones posteriores. $Y$ es probable que nunca hubiese sido sistematizada en un trabajo concreto si Warburg no hubiese retomado dicho material cuando permaneció internado entre 1921 y 1924 a causa del colapso que le provocaron fobias, obsesiones y alucinaciones.

Luego de estar en varias casas de recuperación, la familia Warburg optó por la clínica suiza del doctor Ludwig Binswanger. Si bien a lo largo de los primeros meses Binswanger aceptó el diagnóstico de una condición incurable, hacia 1923 la situación comenzó a cambiar (BINSWANGER; WARBURG, 2008, p. 11). En este periodo el paciente organizó sus crípticos apuntes en la conferencia que más tarde sería conocida como El ritual de la serpiente. ${ }^{4}$ La lección dictada el 21 de abril de 1923, tuvo por finalidad demostrar la plena capacidad lógica de Warburg luego del tratamiento recibido (DIDI-HUBERMAN, 2004). En la primera parte de ella explicó - entre otras cosas - cómo los indios Hopi en sus ritos ceremoniales relativos a la cosecha, manipulaban serpientes vivas con la intención de someter mágicamente la naturaleza. ${ }^{5}$ Las serpientes, luego de las súplicas a los cielos, eran liberadas para que actuaran como mensajeras entre los hombres y la tormenta.

Después de la exposición Binswanger (2008, p. 125-126), notó que si bien,

los puntos principales estaban demasiado recubiertos de argumentos accesorios, a los puntos de vista importantes se ha hecho referencia solamente por acotaciones y con alusiones profundamente arqueológicas que sólo poquísimos entre los presentes podían comprender,

4 El título que el mismo Warburg dio a la conferencia, como ha subrayado Michael Steinberg, fue Imágenes desde la región de los indios Pueblo de Norteamérica. Ha sido destacado el hecho que el historiador nunca presenció el ritual de la serpiente, lo único que observó fue la danza humiskachina del trigo (STEINBERG, 1995, p. 95-96).

5 La conferencia puede ser dividida en dos partes. La primera relativa a las ceremonias y objetos observados en Nuevo México, y la segunda dedicada al significado simbólico de la serpiente en diversas culturas.

Rev. Filos., Aurora, Curitiba, v. 22, n. 31, p. 575-589, jul./dez. 2010 
El dominio del paciente había sido sorprendente. Por su parte Warburg, aunque al día siguiente escribió en su diario que "la conferencia fue un brillante suceso" (STEINBERG, 1995, p. 97), cuatro días más tarde se mostraba más escéptico, reconociendo la complejidad de las palabras pronunciadas, pero, al mismo tiempo, admitiendo que la investigación "podría tener algún valor a condición que fuese enriquecida con documentos sobre la historia del pensamiento simbólico" (WARBURG, 2006a, p. 67). Más allá de las apreciaciones o aprensiones que pudo producir la lección en su autor o en quienes lo escucharon, fue un hecho concreto que la larga terapia centrada en la capacidad de auto-sanación de los enfermos de la Clínica Bellevue le había permitido volver al trabajo científico incorporando nuevos matices a su idea de la creación artística.

\section{El problema del hombre y la manipulación}

Es conocida la importancia que el Sartor Resartus de Thomas Carlyle jugó en la filosofía de Aby Warburg. Para el crítico británico las vestimentas no son objeto de la necesidad o la decencia, sino que su fundamento primero es el adorno. El salvaje aborigen, anota el escocés:

encontró calor en las fatigas de la caza; o en la gruta natural; pero para el adorno debía tener los trajes [...] en general el hombre es un animal que emplea utensilios [...] sin ellos es nada, con ellos lo es todo (CARLYLE, 1976, p. 50).

La unión entre el hombre y sus herramientas puede ser entonces entendida como un vínculo ontológico en el cual el primero se siente completo y capaz de ser comprendido en la incorporación del segundo. Este sentido de la comprensión humana tiene una clara correlación con el valor entregado por Warburg a la extensión del yo.

La sintonía con el pensamiento del británico se deja ver en una carta que el historiador le envió a Ernst Cassirer a comienzos de 1924: "Sin duda", escribe, "conocerá el Sartor Resartus de Carlyle: él sí que sabía qué cosa es un símbolo" (CASSIRER, 2003, p. 49). Warburg no sólo encontraría en esta obra los fundamentos de la teoría de la manipulación y su relación con la tragedia, sino también una unión de ésta con el ámbito simbólico. Al definir este último, Carlyle (1976, p. 232) dice: 
En un Símbolo hay misterio, y, sin embargo, hay revelación: de ahí, pues, un doble significado, por la acción simultánea del silencio y la palabra. Y si a la vez, la Palabra es por sí misma elevada y el Silencio decoroso y noble, ¡cuán expresiva será su unión! [...] Por los símbolos, la Imaginación y su mística región de las maravillas, pasan al estrecho y prosaico dominio de los sentidos y se identifican con él. En el Símbolo propiamente dicho, en lo que podemos llamar un Símbolo hay siempre, más o menos nítida y directamente, alguna encarnación, alguna revelación de lo Infinito. ${ }^{6}$

Emana aquí uno de los puntos más importantes para la explicación de la desaparición del concepto de tragedia en la definición de obra de arte de Warburg. Carlyle (1976, p. 50) reconoce que el actuar del hombre nunca procede por mero azar, pues su mano está siempre guiada por "misteriosas operaciones del espíritu". Las herramientas y los símbolos, en este sentido, formaban parte de una misma familia. Así las cosas, Gombrich acertó al afirmar que en el sentido místico dado por Carlyle a los símbolos, Warburg encontraría un modo de adentrarse en el análisis y comprensión de una "psicología científica de la cultura" que fuese expresión del irracionalismo que invade tanto la religión como el arte (GOMBRICH, 2003, p. 74). Es precisamente dicho aspecto irracional el que subraya su condición espiritual y la posibilidad de distinguirlo de las expresiones conscientes. El misterio sólo puede ser tal en la medida que sea perceptible, es decir, en su corporización.

Con Carlyle comprendemos el lugar que los objetos tienen en la vida del hombre y, al mismo tiempo, vislumbramos las implicancias que su uso supone: la pérdida del sentido orgánico de sí. La definición del hombre a partir de sus ornamentos demuestra los peligros de la corporización, pues puede considerarse que los atuendos dicen de quienes los llevan más que el hombre mismo que los viste. Pero, como hemos visto, la corporización puede ser entendida también como un acto mágico en donde se incorpora el objeto, quedando asimilado y supeditado a la necesidad del sujeto. Ahora bien, estas necesidades no son inmediatas y, por lo tanto, la creación de herramientas no obedece al apremio de un instante sino a la previsión. Esto implica un acto de representación - la elaboración del utensilio - que anticipa el futuro: es una

6 Junto a la influencia que Carlyle tuvo en el desarrollo del concepto de símbolo en Warburg, es necesario agregar a ésta la teoría de Theodor Vischer expuesta en su libro Das Symbol (2003), que jugó un papel fundamental en las ideas del historiador. Sobre la influencia de Vischer en Warburg ver especialmente WIND, 1993; RAMPLEY, 1997. 
representación imaginaria del momento en que será utilizado (CASSIRER, 1975 , p. 43-44). Visto de esta forma, la tragedia parece desaparecer en lo que ahora puede ser entendido como un nuevo valor de la corporización. Este giro valórico de la categoría empleada precisa el sentido primigenio de la imagen en general y del símbolo en particular, en donde la espiritualidad religiosa es un agente de primer orden en su génesis. La imagen del recuerdo en el hombre primitivo conduce a una corporización que lo conecta con lo espiritual (WARBURG, 2006a, p. 50). Toda conexión supone comunicación y toda comunicación activa implica un vínculo espiritual (CASSIRER, 1975, p. 83-84).

\section{El arte como mímica de la animalidad y ciencia de los límites}

En un breve ensayo de 1927 sobre Nietzsche y Jacob Burckhardt, Warburg afirmaba que la percepción del pasado bajo los parámetros del filósofo podían llevar a la destrucción del yo. Como su propia experiencia se lo había demostrado pocos años antes, "la exposición solitaria a los golpes más terribles [del pasado] es aquello que condujo a Nietzsche [...] a la perdición" (WARBURG, 2007, p. 901). Las aflicciones que provocan las batallas, la animalidad - en definitiva los dolores de Dionisio, la forma más antigua de la tragedia griega según Nietzsche -, atraviesan la cultura humana (DIDIHUBERMAN, 2006, p. 143). Mientras Burckhardt fue consciente del peligro que estas ondas del pasado provocaban en el individuo y por lo tanto nunca transgredió sus límites, Nietzsche se derrumbó al no saber enfrentar la fórmula "patética" (WARBURG, 2007, p. 901). Warburg no sólo se identifica con ambos autores, también su idea del arte es el resultado de la forma que tiene de comprenderlos.

Georges Didi-Huberman ha propuesto que la sobrevivencia de lo trágico es la característica fundamental de la cultura para Warburg. En tal sentido, la lucha entre lo apolíneo y lo dionisiaco es el motor que mueve las investigaciones del historiador en su intento por equilibrar la fuerza de la tradición y la originalidad que se le exige al arte. Así, el conflicto entre pathos y ethos se plasma en movimientos corporales, gestos anímicos que proceden de nuestra propia inmemorialidad y quedan registrados en figuras concretas, en imágenes vitales. El movimiento expresado a través de la fórmula pathos es aquello que permanece en el tiempo; he aquí el valor de las Ménades danzantes en los sarcófagos antiguos que conservan la energía original del rito transmitiendo sus emociones originales. Es precisamente la metamorfosis de sus formas en la 
Historia lo que da cuenta de su ánimo vivo y cambiante (DIDI-HUBERMAN, 2006, p. 143).

Al ser el arte de los indios un intento por crear un orden en el caos de la vida (WARBURG, 2006a, p. 28), analizarlo aparecía como una forma concreta de estudiar el arte a través de la combinación entre la mímica dionisíaca y la razón teorética. En dicho tentativo la serpiente se revela como la metáfora que mejor ilustra la constante renovación y permanencia en la cultura. En una nota relativa a esta idea, Warburg explica que la serpiente tiene la capacidad de pasar del más profundo letargo a la más activa vitalidad, puede cambiar su piel permaneciendo ella misma y aunque no puede caminar tiene una energía que la impulsa, posee, además, el arma del veneno y de la invisibilidad frente al ojo humano camuflándose en el desierto o escondiéndose en su madriguera: "Todas estas propiedades la convierten en un símbolo relevante e indestructible de la ambivalencia de la naturaleza, de la vida y de la muerte, de lo visible y lo invisible, del disimulo y la fatalidad" (WARBURG, 2006b, p. 54 n. 1). Así, los contrastes de los que habla Warburg son, en este sentido, equivalentes a la consonancia entre vida humana individual y cultura. Su estudio sobre el Arte del retrato y burguesía florentina mostraba esta mima idea en el terreno del arte renacentista:

Cuando las concepciones opuestas de la vida llevan a los miembros de la sociedad a un partidismo apasionado y conducen a una lucha a vida o muerte, provocan una decadencia irremediable de la sociedad. Y, sin embargo, dichos contrastes pueden ser al mismo tiempo la fuerza que haga florecer la cultura; sólo cuando el enfrentamiento de dichas fuerzas en vez de destruirse recíprocamente queda neutralizado y armonizado en la mente del individuo, tal enfrentamiento propicia una fertilización mutua y una extensión de todo el ámbito de la personalidad (WARBURG, 2000, p. 119).

Mientras se perciban los contrastes como conciliables, la fuerza creativa mantendrá su impulso: Nietzsche y Burckhardt se reconcilian en el retorno de Warburg al trabajo científico. Pero no se trata de una simple pretensión de unanimidad, sino de un sentido de percepción espiritual que vislumbra en toda creación un rasgo vital.

El símbolo es también el resultado de una reconciliación. Es un instrumento que muestra la permanencia activa del combate que el individuo libra contra la perplejidad que le provoca la naturaleza. El reconocimiento de esa perplejidad es generado por el recuerdo traumático de la separación de dos 
criaturas; en palabras de Warburg: "el espacio del pensamiento abstracto entre sujeto y objeto tiene origen en la experiencia del corte del cordón umbilical"? Así, el sentimiento de orfandad que experimenta el hombre le obliga a establecer un nuevo vínculo paternal adoptando simbólicamente un animal que le transmite las capacidades necesarias - aunque débiles y dispersas - para luchar contra la naturaleza (WARBURG, 2006a, p. 30). En el caso del ritual de los indios Hopi tanto la manipulación de la serpiente como su identificación con el rayo y consecuentemente con la lluvia y la fertilidad, suponen una conexión capaz de ordenar aquello que se estimaba disperso en la realidad con el fin de alcanzar la comprensión de los eventos naturales. El rayo de la tormenta y el movimiento del reptil son uno y el mismo; la naturaleza y el hombre pueden ser comprendidos bajo este aspecto como un todo concordante.

Contrariamente a la confusión mágicamente ordenada en el rito donde se unen el hombre, la serpiente y el rayo -, en el pensamiento moderno los instrumentos son objetos delimitantes que lo separan al hombre de la naturaleza. Éste, piensa Warburg, no necesita de la manipulación pues sus certezas científicas no requieren de imagen alguna para conectar las distintas esferas de la realidad: el rayo ha sido atrapado y sometido en los cables eléctricos. Prescindir de la imagen es reducir el símbolo a mero significado. Los Hopi toman la serpiente apropiándose de ella y poniéndosela en la boca para alcanzar una unión efectiva con el rayo por el sentido simbólico que le atribuyen a una entidad viviente. En el "progreso de la cultura", el carácter mental del símbolo le permite prescindir de la visión (WARBURG, 2006b, p. 61). El ejercicio mímico conducente a alcanzar una influencia mágica para apropiarse de un fenómeno natural en su forma viviente (orgánico) tiene su contrapartida en la certeza moderna, capaz de atraer el rayo al suelo con un instrumento magnético (inorgánico) (WARBURG, 2006b, p. 66). Sin embargo, no podemos afirmar que la relación mediadora del símbolo haya desaparecido, sólo ha cambiado.

Estas dificultades nos ayudan a comprender porqué para Warburg el acto artístico es el punto medio de una manipulación o apropiación del mundo. Ella no acepta hablar ni de lo orgánico, ni de lo inorgánico:

Entre el asir y el comprender está la delimitación de la extensión.

El proceso artístico se sitúa entre la mímica y la ciencia. Aquél utiliza la

7 Aparentemente Warburg conocía las teorías de Otto Rank. Aunque desconozco el nivel de familiaridad con ellas, es probable que algunas deriven del contacto con el Dr. Binswanger, seguidor de Freud y de quien Rank era discípulo (cfr. STIMILLI, 2008, especialmente p. 10 y 23 ). 
mano, ésta retorna a su decurso; imita, es decir, renuncia a todos los derechos de apropiarse del objeto bajo el pacto de poder determinar por el tacto su contorno exterior. No renuncia del todo el sujeto a tocar, sino a apropiarse para la comprensión.

El acto artístico es en cierto modo un tomar neutro que no modifica realmente la relación entre el objeto y el sujeto, pero lo absorbe a través de la mirada y lo restituye - en la escultura por medio de una efectiva tactilidad, en la pintura gracias al hecho de trazar sus contornos (WARBURG, 2006a, p. 62).

Sólo si asumimos el desinterés - por cuanto no hay intención de apropiarse del objeto - como el atuendo que cubre la creación artística, comprendemos el camino trazado por Warburg. En sus creaciones, el hombre toma algo de la realidad siendo consciente de la necesidad de renuncia que implica. Está dispuesto a recorrer sólo los límites, pura y exclusivamente para poder trazar los contornos. Aquí radica el aspecto científico del mismo, en su descripción y clasificación que, al mismo tiempo, no puede prescindir de un carácter utilitario. La función conferida a la creación artística está basada en ser un garante que otorga la posibilidad al hombre de conocer intuitivamente a través de lo que se esconde en la elocuencia silenciosa de los bordes. La neutralidad del arte producto de la negación de apropiación, supone un doble desistir: la del hombre religioso que abandona la manipulación para conectar y la del hombre civilizado que comprende manipulando técnicamente para explicar (WARBURG, 2006a, p. 50). Ambas renuncias, sin embargo, dejan huella de su paso en la obra de arte. La idea de tragedia en esta vertiente no desaparece sino que adquiere nuevos matices.

\section{Imagen y religión como manipulación trágica}

Si consideramos que para Warburg el espíritu de la imagen tiene su origen en la energía que se libera en el culto religioso a través, por ejemplo, de la danza, entendemos porqué para él la representación del movimiento determina la vitalidad y sobrevivencia de los motivos artísticos. Sólo la comprensión de la forma psíquica del recuerdo entrega la clave para entender el equilibrio de los elementos que se encuentran en los extremos del acto creativo. Como vimos, según Warburg la memoria "crea espacio al pensamiento" al crear una distancia temporal que da lugar a la reflexión. Pero no sólo, también "refuerza los polos límites del comportamiento psíquico", esto es, la 
contemplación y el abandono dionisíaco, que ahora ya podemos identificar con la expresión espiritual manifestada en el gesto corporal. En otras palabras, la energía liberada en el culto religioso es ordenada en la memoria a través de imágenes constituidas en la conciencia. Religión e imagen se vuelven un elemento indispensable para vislumbrar no sólo el fundamento del arte, sino también al hombre. Cada vez que irrumpe ante nosotros un elemento desconocido, el conocimiento suple la ausencia de imágenes en nuestra memoria, dándole un sentido que aleja el pavor creado por la ignorancia: el miedo a lo conocido es controlable, a lo desconocido es inasible. El mito actúa en este territorio. Los estímulos visuales o acústicos son proyectados en la conciencia a partir de causas irreales, esto es, una causa biomorfa cuya extensión real y comprensible permite una forma de defensa imaginaria: "cuando una puerta cruje a causa del viento, dicho estímulo suscita un sentido de ansia en los salvajes o en los niños porque imaginan un perro gruñendo" (WARBURG, 2006a, p. 40). ${ }^{8}$ Una situación análoga aparece en la creación de imágenes, puesto que tal figuración pretende ingenuamente la posibilidad de manipularlo para comprender su naturaleza; las obras de arte con motivos o fines religiosos son un paradigma de esta misma idea. En otras palabras, tanto en la religión como en el arte la manipulación puede ser sólo imaginaria.

Es posible entender ahora, desde una nueva perspectiva, la relación entre la manipulación y el sentimiento orgánico del yo. La explicación que Warburg da del origen religioso de la imagen, reviste el mismo carácter que vimos en Carlyle. El arte es la herramienta que el hombre utiliza para explicar su propia existencia. Su sentido trágico es una característica de la creación artística: todo aquello que intuimos al observar una obra de arte, todo aquello que no logramos comprender, lo incompleto de la obra, es producto de lo que podemos llamar su semblante divino, su nueva máscara dramática.

En la Introducción a Mnemosyne se entrecruzan con claridad estas ideas. La creación artística es:

Equidistante tanto de la manera de asir los objetos típico de la imaginación, como de aquella característica de la contemplación conceptual. Tal duplicidad se constituyó por un lado como la lucha contra el caos - dado que la obra de arte escoge y clarifica los contornos del objeto - y por otro, como pretensión, con el fin que el espectador acepte el culto del ídolo que

8 Warburg recoge esta teoría del antropólogo italiano Tito Vignoli (GOMBRICH, 2003, p. 67).

Rev. Filos., Aurora, Curitiba, v. 22, n. 31, p. 575-589, jul./dez. 2010 
tiene al frente. Tal ambivalencia es precisamente lo que crea desagrado al hombre espiritual, un desagrado que debiera constituir el objeto principal de la ciencia de la cultura, esto es, de una historia psicológica por imágenes que sea capaz de ilustrar la distancia que existe entre el impulso y la acción (WARBURG, 2002, p. 3).

La primera sentencia refuerza la importancia de la tradición al decir que el arte no puede identificarse exclusivamente con la imaginación, asimismo le reconoce la misma lejanía respecto de lo divino e inmutable - aunque ambos participen en él. Este paso es una re-elaboración de la definición dada en los apuntes para la conferencia de abril de 1923. Desde nuestro punto de vista la influencia de Cassirer - quien identificó en nuestro pensador un colegionario en la lucha por revelar los enigmas de las expresiones del espíritu, y uno de los pocos conocedores del texto que presentó en la clínica psiquiátrica9 ${ }^{9}$ se hace aquí sentir de manera fuerte y particular. La sutileza del pensamiento de Cassirer apostilla el lenguaje a veces críptico de Warburg. En él el concepto de desagrado ocupa el lugar de la tragedia. Éste, apareció delicadamente demarcado en un estudio del filósofo en torno a los conceptos de eidos y eidolon en los diálogos platónicos. Al finalizar sus reflexiones, Cassirer intenta desligar la imagen del ámbito puramente artístico con el fin de flexibilizar la tensión que el sistema platónico había puesto entre ambos conceptos y la traslada hacia el espacio del conocimiento matemático, del conocimiento puro. Allí, dice, tampoco es posible evitar las ayudas y apoyos sensibles, porque únicamente en la imagen es posible representar la naturaleza de aquello que es universal y carente de figura. Sin embargo, insiste Cassirer, incluso el dialéctico (o filósofo) - que en base a la deducción lógica se dedica a observar lo inmutable - es capturado por la fuerza de la imagen apenas intenta explicar con palabras el resultado de su visión con el fin de dar vida a una doctrina y comunicarla: cada reproducción por medio de la palabra es en todo y por todo una reproducción mediata que permanece absolutamente inadecuada y desagradada frente al objeto mismo que ella intenta describir y explicar. La imagen fonética y lingüística y la imagen sensible comparten, desde el punto de vista del conocimiento

9 En una carta a su cercano colaborador Fritz Saxl fechada 26 de Abril de 1923, Warburg nombra las personas que podrán conocer el manuscrito de la conferencia dictada cinco días antes: "Podrá mostrar esta horrenda convulsión de una rana decapitada solamente a mi querida esposa, en parte al doctor Embden a mi hermano Max y al profesor Cassirer" (WARBURG, 2006b, p. 67). Véase también GHELARDI, 2004. 
puro, los mismos límites. Lo trágico es buscar algo último e incondicionado en la representación de ese incondicionado, cuando estamos siempre condicionados por la expresión mediata. Esta tragedia interesa tanto al dialéctico como al artista (2003, p. 163-165).

Como muestra una carta del 29 febrero de 1924, Warburg conocía perfectamente el contenido del texto de Cassirer. En ella le cuenta que había recién terminado de leer su trabajo y le agradecía el permiso para publicarlo en el segundo volumen de los Vorträge de la Biblioteca Warburg. Ambas posturas comparten aquella ambivalencia que desagrada al hombre. El sustrato religioso que Warburg le otorga a la manipulación en la creación artística al identificar la obra con un ídolo que espera ser aceptado, transforma la tragedia en riqueza artística en el mismo sentido dado por Cassirer. Así como la obra es para Warburg un camino hacia la sophrosyne, también para el filósofo la mediación de la imagen o la palabra puede ser entendida como un estadio preliminar indispensable para el pleno conocimiento filosófico que no es otra cosa que la búsqueda del auto-conocimiento (CASSIRER, 2003, p. 165).

\section{Consideración final}

Si en la imagen simbólica vive misteriosamente el espíritu, esto es posible, como afirmaba Carlyle, gracias a la intermediación de la mano. De esta forma, el vínculo natural que para Warburg existe entre arte y religión puede hacerse explícito siguiendo la descripción de los desvíos que la mano toma en el momento de plasmar la creación artística. Pensado así, la imagen de un gesto es una expresión del espíritu acuñada por el gesto. El concepto de manipulación, entonces, se muestra como una herramienta esencial no sólo para comprender la relación del hombre con el mundo externo, sino también para acercarse a los elementos que componen la idea de arte en Aby Warburg. Allí el vínculo entre objeto y sujeto es tan estrecho que parece necesario. La pérdida del sentimiento orgánico del yo se transforma en una exploración a través de la obra. Ahí se dibuja la tragedia del arte, pero es en este rasgo donde germina su riqueza.

\section{Referencias}

BINSWANGER, L.; WARBURG, A. La guarigione infinita: Storia clinica di Aby Warburg. Vicenza: Neri Pozza, 2008. 
CARLYLE, T. Sartor resartus. Madrid: Editorial Fundamentos, 1976.

CASSIRER, E. Las ciencias de la cultura. 4. ed. México: Fondo de Cultura Económica, 1975.

CASSIRER, E. Eidos ed eidolon. Il problema del bello e dell'arte nei dialoghi di Platone. In: WARBURG, A.; CASSIRER, E. Il mondo di ieri. Lettere. Turín: Nino Aragno, 2003. p. 129-168.

DIDI-HUBERMAN, G. Conoscenza par fusée. Warburg e Binswanger. In: CIERIVIA, C.; MONTANI, P. (Ed.). Lo sguardo di Giano. Aby Warburg fra tempo e memoria. Turín: Nino Aragno, 2004. p. 249-276.

GHELARDI, M. Una amicizia 'simbolica': Aby Warburg e Ernst Cassirer ad Amburgo. In: CIERI-VIA, C.; MONTANI, P. (Ed.). Lo sguardo di Giano. Aby Warburg fra tempo e memoria. Turín: Nino Aragno, 2004. p. 221-248.

GOMBRICH, E. Aby Warburg. Una biografia intellettuale. Milán: La Feltrinelli, 2003.

NABER, C. Pompeji in Neu-Mexico: Aby Warburgs amerikanische Reise. Freibeuter, v. 38, p. $88-97,1988$.

RAMPLEY, M. "From Symbol to Allegory: Aby Warburg's Theory of Art". The Art Bulletin, v. 79, n. 1, p. 41-55, 1997.

SETTIS, S. Verso una storia naturale dell'arte: Aby Warburg davanti a un rinascimento indoamericano (1895). In: WARBURG, A. Gli Hopi. La sopravvivenza dell'umanità primitiva nella cultura degli indiani dell'America del Nord. Turín: Nino Aragno Editore, 2006. p. 7-13.

SEVERI, C. L'antropologia possibile di Aby Warburg. In: CIERI-VIA, C.; MONTANI, P. (Ed.). Lo sguardo di Giano. Aby Warburg tra tempo e memoria. Turín: Nino Aragno, 2004. p. 477-522.

STEINBERG, M. Aby Warburg's Kreuzlingen lecture: a Reading. In: WARBURG, A. Images from the Region of the Pueblo Indians of North America. Ithaca: Cornell University Press, 1995. p. 59-114.

STIMILLI, D. "La tintura de Warburg”. In WARBURG, A.; BINSWANGER, L. La guarigioni infinita. Storia clinica di Aby Warburg. Vicenza: Neri Pozza, 2008, p. 9-36.

VISCHER, T. Il simbolo. In: VISCHER, R.; VISCHER, F. T. Simbolo e forma. Turín: Nino Aragno, 2003. p. 107-166. 
WARBURG, A. Arte del ritratto e borghesia Fiorentina: Domenico Ghirlandaio in Santa Trinita: I ritratti di Lorenzo de'Medici e dei suoi familiari. In: WARBURG, A. La rinascita del paganesimo antico. Florencia: La Nuova Italia, 2000. p. 109-146. WARBURG, A. Mnemosyne. L'Atlante delle immagini. Turín: Nino Aragno, 2002. WARBURG, A. Gli Hopi. La sopravvivenza dell'umanità primitiva nella cultura degli indiani dell'America del Nord. Turín: Nino Aragno, 2006a.

WARBURG, A. Il rituale del serpente: una relazione di viaggio. Milán: Adelphi, 2006b.

WARBURG, A. Burckhardt e Nietzsche. In: WARBURG. A. La rinascita del paganísimo antico e altri scritti (1917-1929). Turín: Nino Aragno, 2007. p. 895-901.

WIND, E. El concepto de Kulturwissenschaft en Warburg y su importancia para la estética. In: WIND, E. La elocuencia de los símbolos. Madrid: Alianza, 1993. p. 63-78.

Recebido: $22 / 07 / 2010$

Received: 07/22/2010

Aprovado: $16 / 09 / 2010$ Approved: 09/16/2010 